برآورد تبخير و تعرق واقعى در مقياس منطقهاى به كمك دادههاى سنجش از دور در دشت شهركرد الف- مقايسه نتايج مدلهاى SEBAL و METRIC نسبت به اندازهيرىهاى لايسيمترى

\author{
على مرشدى' "، مهدى نادرى'، سيدحسن طباطبايى ' و جهانگرد محمدى

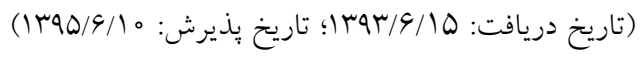

\begin{abstract}
جكيده

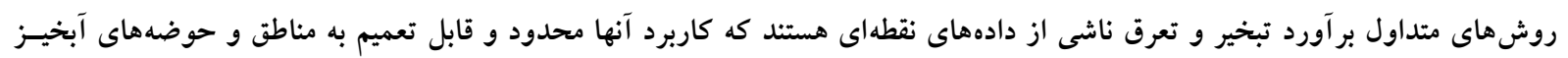

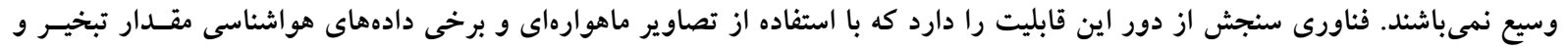

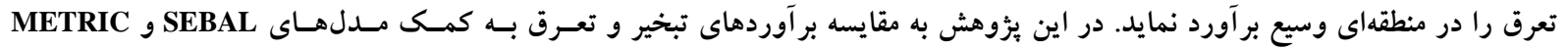

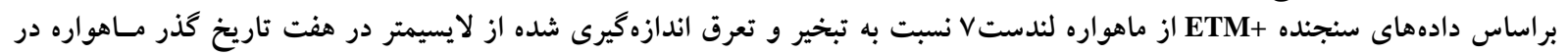

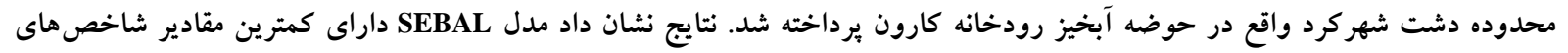

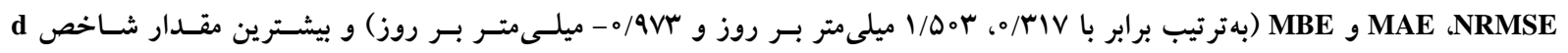

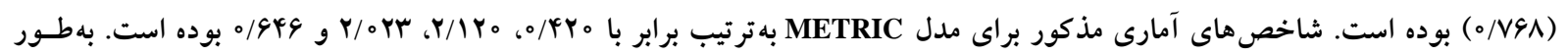

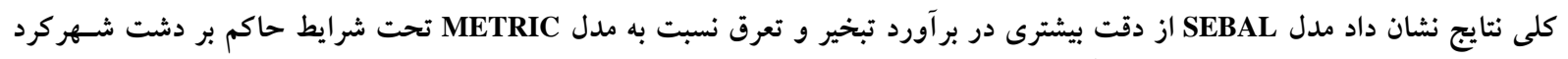

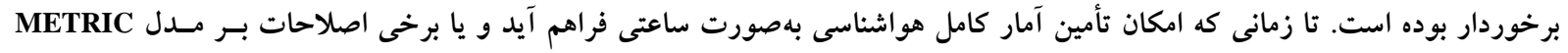

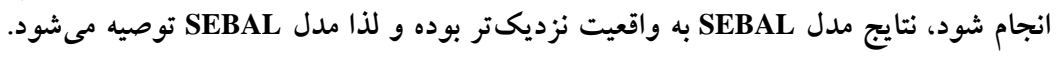

وازههاى كليدى: تصوير ماهواره، لندست، توازن انرزى سطح، يونجه

\footnotetext{
ا... بخش تحقيقات خاك و آب، مركز تحقيقات و آموزش كشاورزى و منابع طبيعى، سازمان تحقيقات، آموزش و ترويج كشاورزى، شهركرد

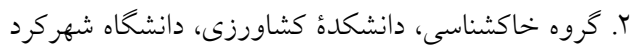

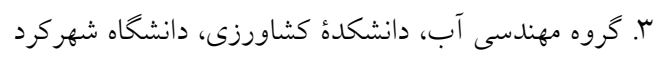

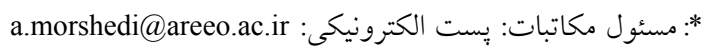


استفاده از دادههاى آن ايستخاه مىداند (Y)). اكبرى و همكـاران

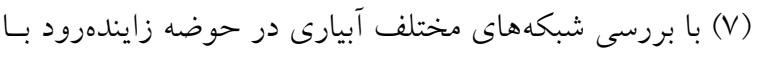

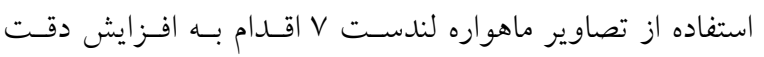

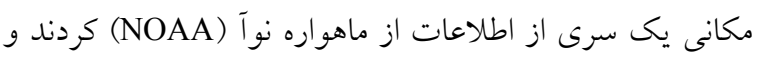

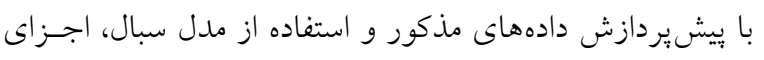

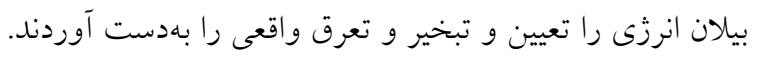

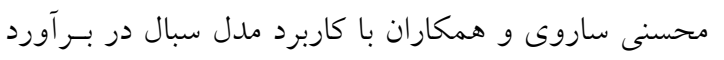

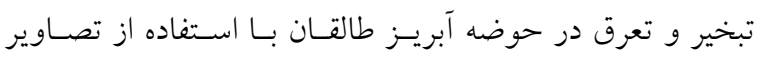

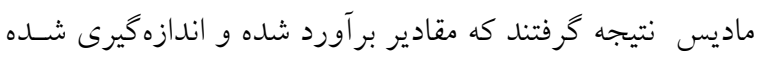

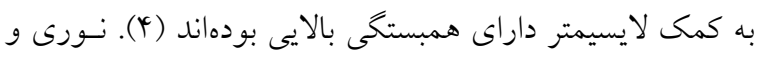

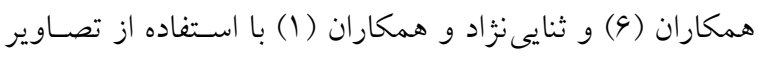

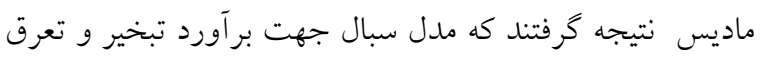

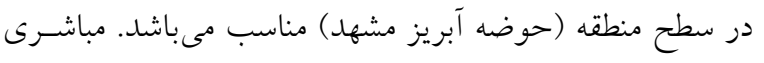

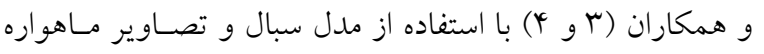

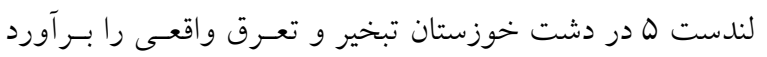

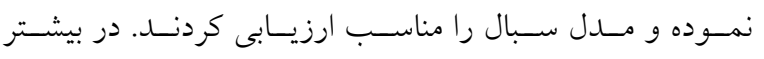

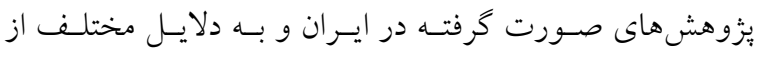

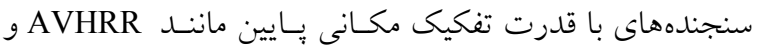

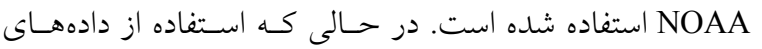

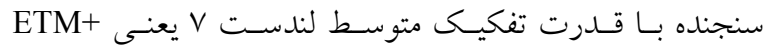
ضرورى است تا دادهاى اين سنجنده بــراى بررسى تغييـرات

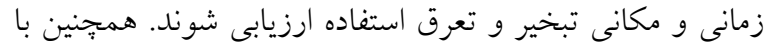
توجه به اينكه مزارع كشاورزى در اغلب دشتهاى اير وان داراى

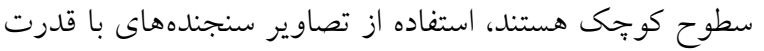
تفكيك متوسط بسيار با اهميت مىباشد.

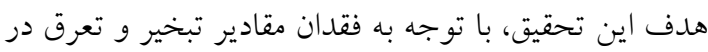
مقياس منطقهاى بـر اى محـــودةٔ مـورد مطالعـه، مقايسـه نتـايج

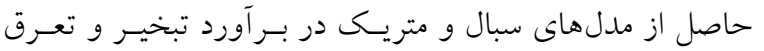
واقعى در دشت شهركرد با استفاده از دادهــاى سـنجش از دور

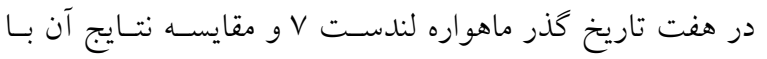
مقادير اندازگيرى شده تبخير و تعرق در لايسيمتر مىباشد.
بيشرفتهاى اخير در مدلهاى برآورد تبخيـر و تعـرق (ET) از

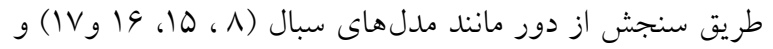

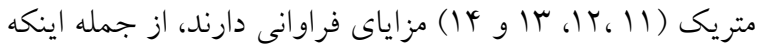

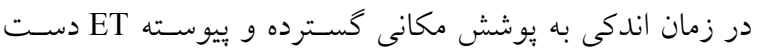

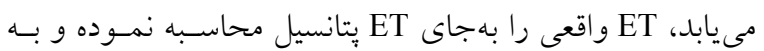

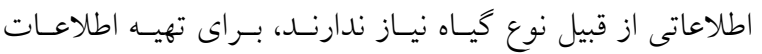

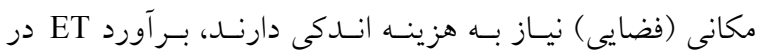

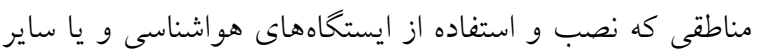

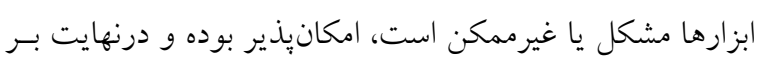

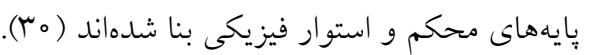

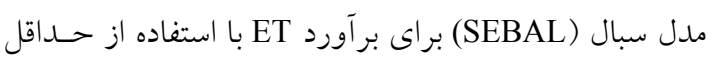

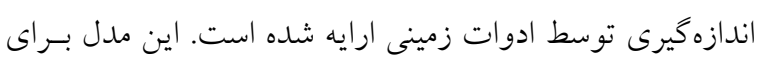

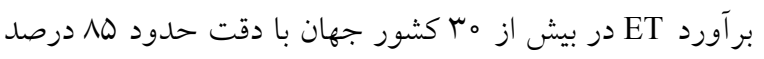

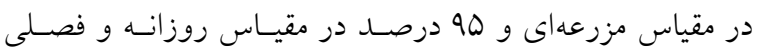

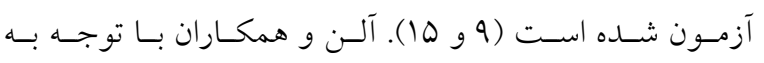

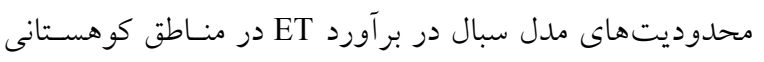

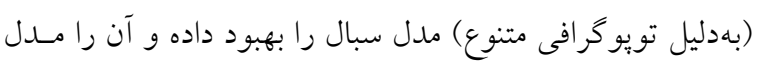

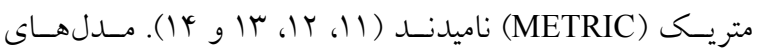
مزبور مقدار ET را براساس دادههاى طيفى در محسـوده مريسى،

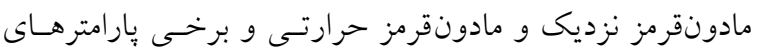

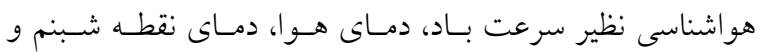
ساعات آفتابى تخمين مىزند.

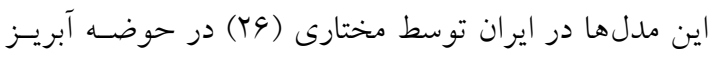
برخوار (شرق اصفهان) با استفاده از تصاوير ماهوارههاى ماديس ماديس و و آستر (MSTER) براى مقايسه مدل سبال بـا مـدل (MODIS)

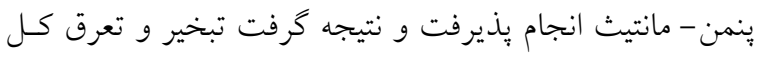

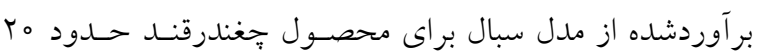

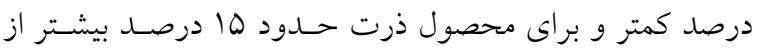

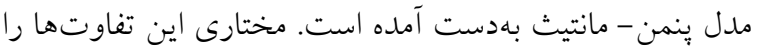
ناشى از تعداد محدود تصاو ير ماهوارهاى براى برونيابى ET بــــ

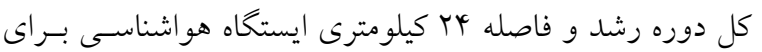




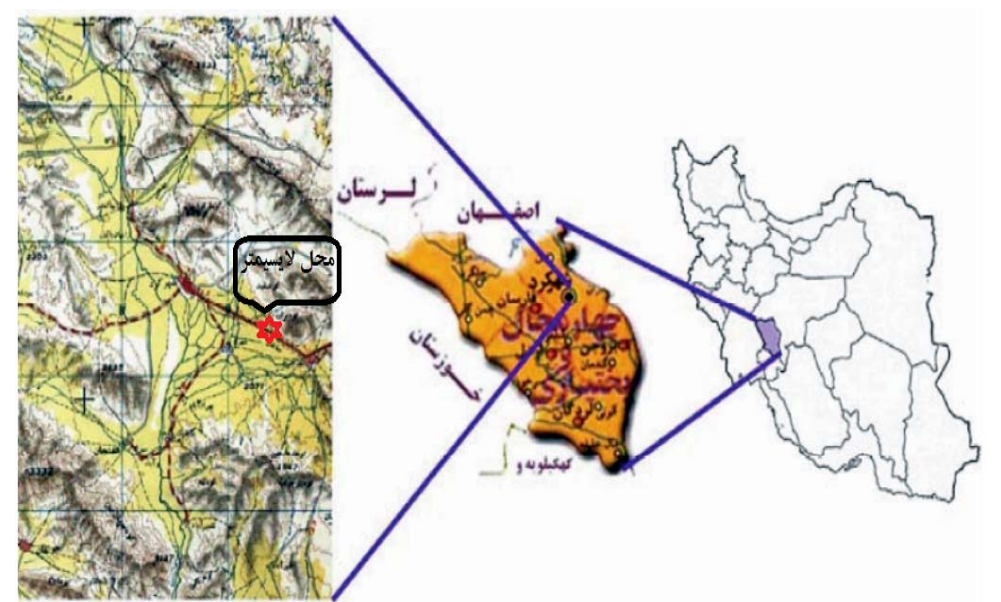

شكل ا. موقعيت جغرافيايى منطقه مورد بررسى و محل نصب لايسيمترها

ارتفاعات جهانبين و تفه، از شرق به ارتفاعات كوه سينه و برات و از غرب به ارتفاعلات كوه قلنكان و ارتفاعـات مشــف بــهـ جـاده فارسان منتهى مى شود. درجـه حــرارت متوسط سـالانه محــودهه

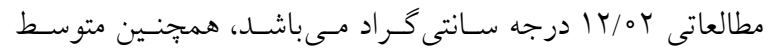

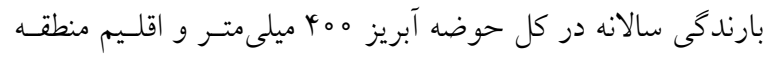

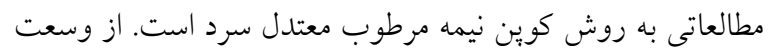

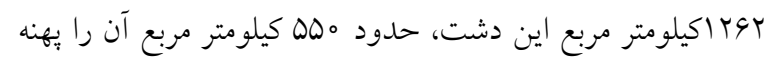

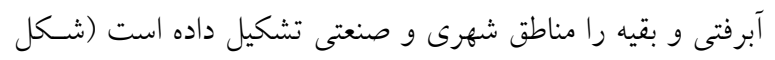

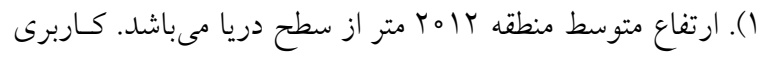

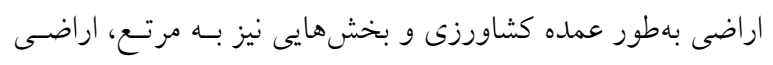
باير و مناطق مسكونى اختصاص يافته است.

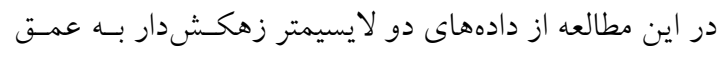

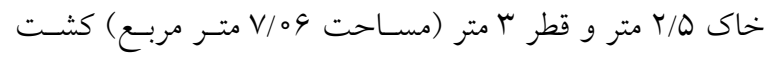

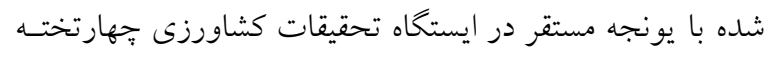

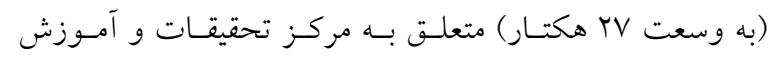

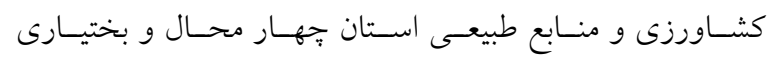

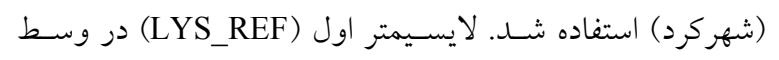

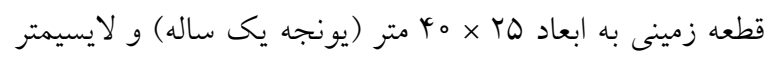

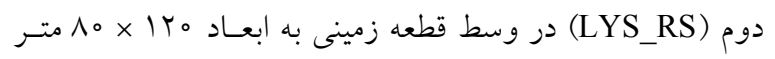

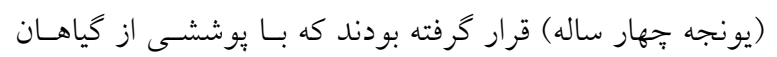

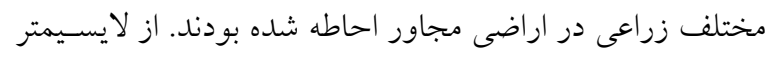

مواد و روشها - - ماد مدلهاى سبال و متريكى از معادله موازنه انـرزى بــراى بــر آورد

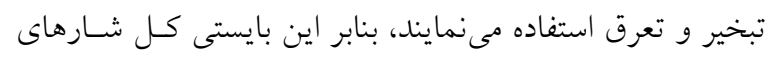

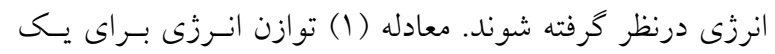
سطح تبخير را نشان مىدهد:

$\lambda \mathrm{ET}=\mathrm{R}_{\mathrm{n}}-\mathrm{G}-\mathrm{H}$ در اين معادله R شار تابش ورودى خالص به سطح مورد نظـ

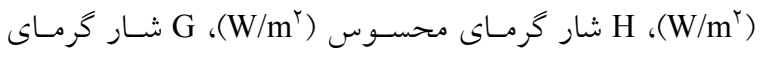

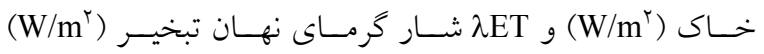
مىباشند. در معادله (1) تنها شار قايم درنظر كرفته و از شارهاى

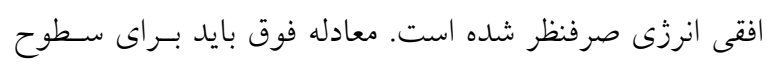

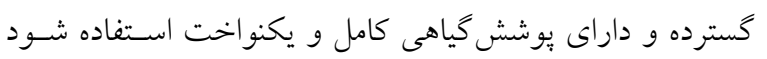

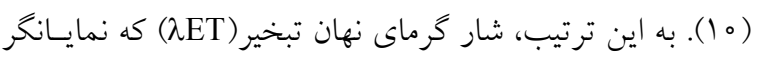

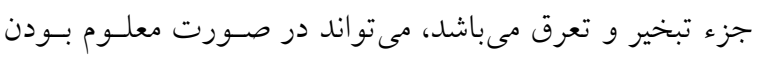

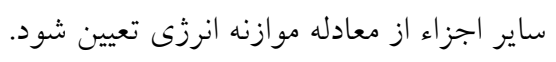
محدودة مطالعاتى دشت شهركرد واقع در حوضه آبخيز كارون

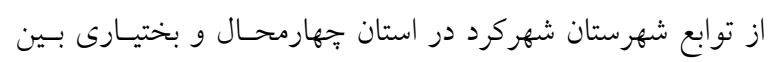

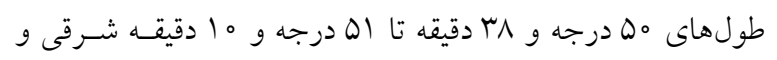

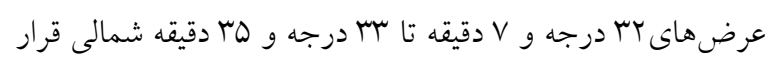

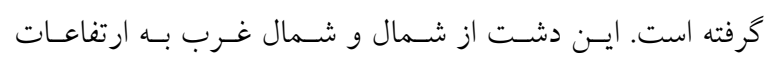

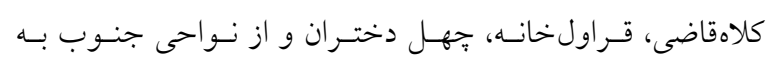


دادهاى هو اشناسى مورد نياز (جدول () شامل رطوبـت نسـبى

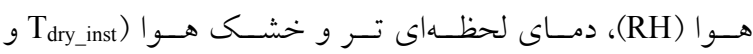

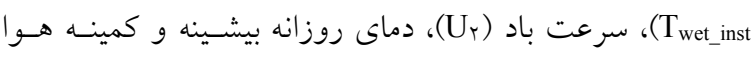

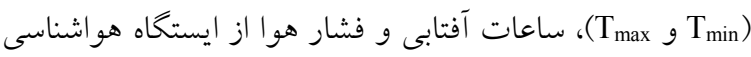

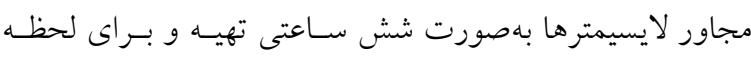

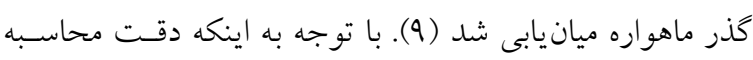
تبخيـر و تعـرق مرجـع (ET

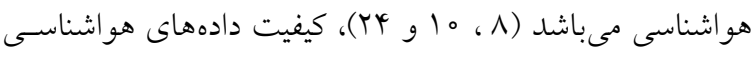

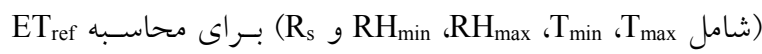

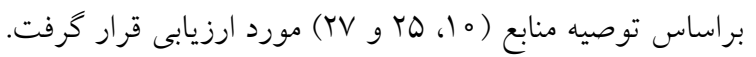

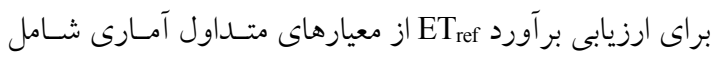
ضريب تعيين (Coefficient of Determination, R $^{\Upsilon}$ )، خطاى مطلق ميانخين (Mean Absolute Error, MAE)، خطاى اريـب ميـانخين و جذر ميانخين مربعات خطاى نرمال (Mean Bias Error ,MBE) شـاه (Normalized Root Mean Square Error, NRMSE) و و شاخص تو افق (Index of degree,d) استفاده شد (TV).

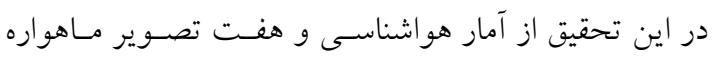

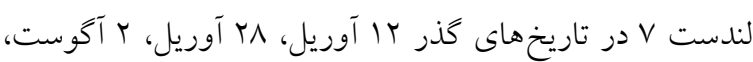

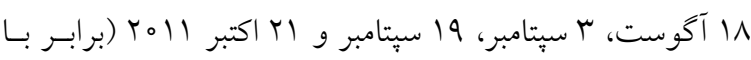

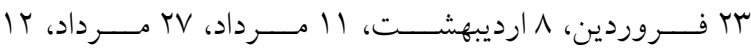

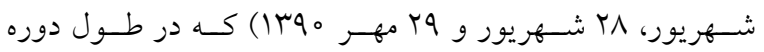
رشـــ محصـول وجـود داشـت، اسـتفاده شــــ (جـــول r).

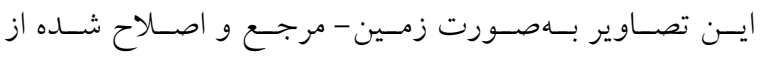

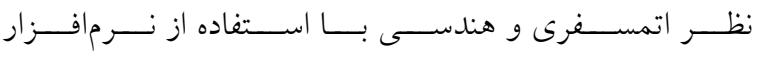
توسط سـازمان (Landsat Ground Processing System) فضايى ايالات متحده در اختيار قرار كرفت. اين تصاوير شامل

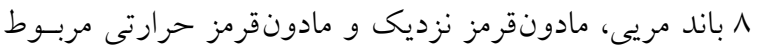

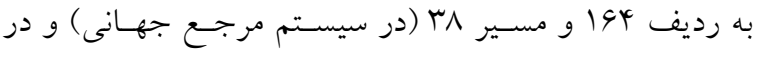

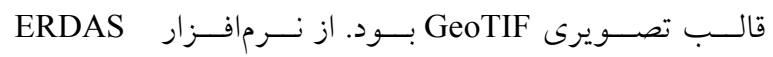
IMAGINE 2010

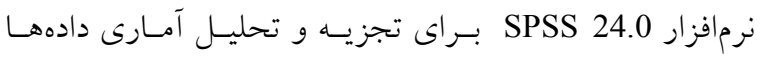

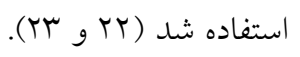

اول (LYS_REF) براى اندازهگيرى تبخير و تعرق مرجع يونجه

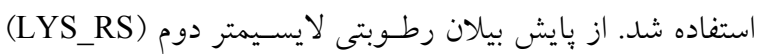

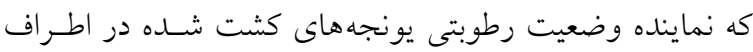

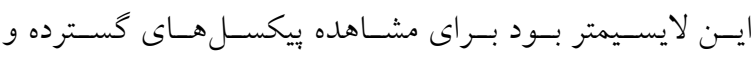

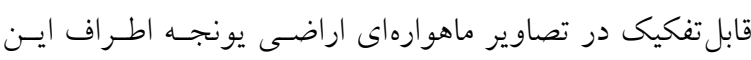

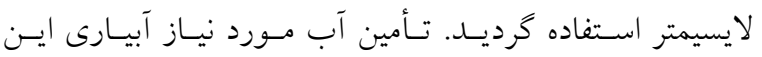

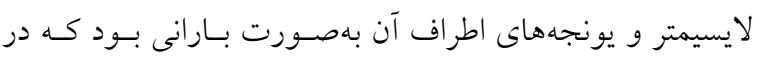

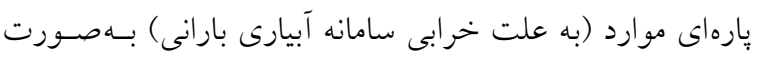
كامل انجام نمى گرفت لذا اراضى يونجه مربوط بـ به اين لائ لايسيمتر

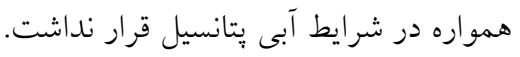

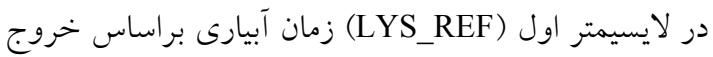

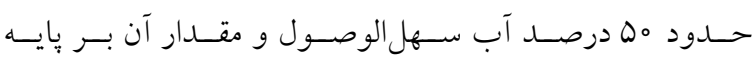

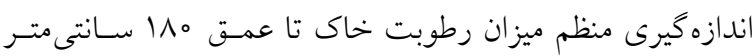

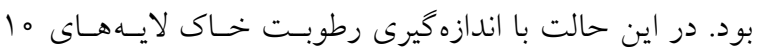

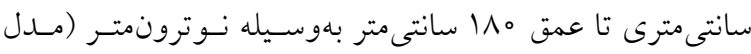

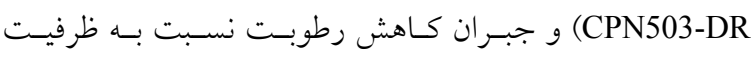

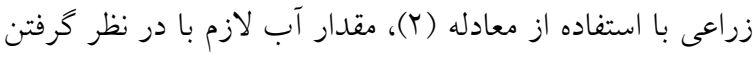

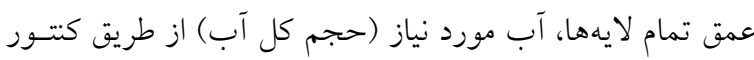

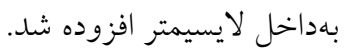

$\mathrm{d}_{\mathrm{n}}=\sum_{\mathrm{i}=1}^{\mathrm{n}}\left(\mathrm{FC}-\theta_{\mathrm{i}}\right) \cdot \mathrm{D} \cdot \mathrm{\rho}_{\mathrm{b}}$

در اين معادله d مقدار آب مورد نياز كيـاه برحسـب ميلسىمتـر، FC ظرفيت زراعى مزرعه برحسب درصد،

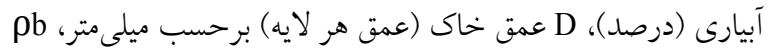

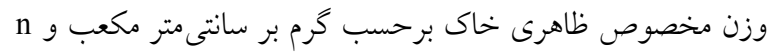

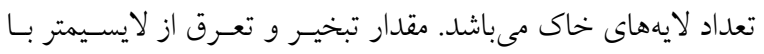

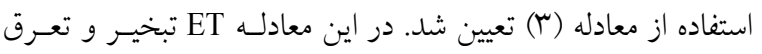

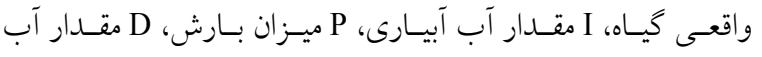

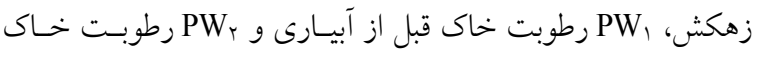

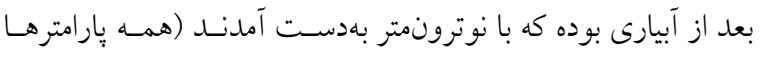

$$
\text { برحسب ميلى متر هستند). }
$$

$\mathrm{ET}=\mathrm{I}+\mathrm{P}-\mathrm{D} \pm \sum_{\mathrm{i}=1}^{\mathrm{n}}\left(\mathrm{PW}_{\mathrm{r}}-\mathrm{PW}_{\uparrow}\right)$ 
برآورد تبخير و تعرق واقعى در مقياس منطقهاى به كمك دادههاى سنجش ...

جدول ا. آمار هواشناسى مربوط به تاريخ گذر ماهواره لندست

\begin{tabular}{|c|c|c|c|c|c|c|c|c|c|c|}
\hline \multirow[t]{2}{*}{$\mathrm{n} / \mathrm{N}$} & $\mathrm{T}_{\text {min_daily }}$ & $\mathrm{T}_{\text {max__Daily }}$ & Air Pres. & RH & $\mathrm{U}_{2}$ & $\mathrm{~T}_{\text {wet_inst }}$ & $\mathrm{T}_{\text {dry_inst }}$ & \multirow[t]{2}{*}{ ساعت } & \multirow{2}{*}{ روز زوليوسى } & \multirow{2}{*}{ تاريخ كذر } \\
\hline & ${ }^{\circ} \mathrm{C}$ & ${ }^{\circ} \mathrm{C}$ & mbar & $\%$ & $\mathrm{~m} / \mathrm{s}$ & ${ }^{\circ} \mathrm{C}$ & ${ }^{\circ} \mathrm{C}$ & & & \\
\hline \multirow{2}{*}{$\circ / \wedge \Delta \mid$} & \multirow{2}{*}{$9 / 1^{4}$} & \multirow{2}{*}{$19 / 0$} & \multirow{2}{*}{$v 9 \circ / 9$} & \&V & $9 / 0$ & $\varphi / r$ & $\Lambda / \Lambda$ & $\circ 9: Y_{0}$ & \multirow{2}{*}{ lor } & \multirow{2}{*}{ זا آوريل } \\
\hline & & & & rq & $Q / \circ$ & $V / T$ & $10 / 4$ & Ir:Y。 & & \\
\hline \multirow{2}{*}{$\circ / N V^{2}$} & \multirow{2}{*}{$1 / 1$} & \multirow{2}{*}{$r Y / 4$} & \multirow{2}{*}{$190 / 9$} & $v^{\mu}$ & $0 / 0$ & $0 / 9$ & $T / 0$ & $\circ 9: Y_{0}$ & \multirow{2}{*}{111} & \multirow{2}{*}{ גז آوريل } \\
\hline & & & & rr & $0 / 0$ & $9 / 1$ & $1 N / T$ & IY:Y。 & & \\
\hline \multirow{2}{*}{-/AVD } & \multirow{2}{*}{$\mid r / 4$} & \multirow{2}{*}{$\mathrm{m} / \mathrm{A}$} & \multirow{2}{*}{ Vqr/V } & rᄉ & $V / \circ$ & $9 / 9$ & $1 \% / 0$ & $09: Y_{0}$ & \multirow{2}{*}{ YIY } & \multirow{2}{*}{ ץه آكوست } \\
\hline & & & & 14 & $0 / 0$ & $14 / 0$ & $r q / 1$ & |r:T。 & & \\
\hline \multirow{2}{*}{$\circ / 4 \wedge \mu$} & \multirow{2}{*}{$19 / 0$} & \multirow{2}{*}{ 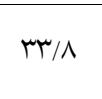 } & \multirow{2}{*}{$\vee \wedge ৭ / 4$} & \&V & $r / 0$ & $10 / 9$ & $19 / 1$ & $\circ 9: Y_{0}$ & \multirow{2}{*}{ rro } & \multirow{2}{*}{ 1ا آكوست } \\
\hline & & & & rI & $0 / 0$ & $I V / x$ & 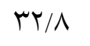 & IY:Y。 & & \\
\hline \multirow{2}{*}{$\circ / \Lambda V Q$} & \multirow{2}{*}{$V / T$} & \multirow{2}{*}{$\mu_{0} / r$} & \multirow{2}{*}{$191 / 9$} & $\Delta T$ & $Y / \circ$ & $r / 9$ & $V / 9$ & $\circ 9: r^{\circ}$ & \multirow{2}{*}{ rYS } & \multirow{2}{*}{ r ستّامبر } \\
\hline & & & & IV & $0 / 0$ & $1 \% / r$ & $r V / S$ & IT:Y。 & & \\
\hline \multirow{2}{*}{$\circ / \Lambda \Lambda 0$} & \multirow{2}{*}{$9 / r$} & $r Q / r$ & Vor & $\Delta Q$ & $0 / 0$ & $Q / /^{\leftarrow}$ & $9 / 4$ & $\circ 9: Y_{0}^{\circ}$ & & \\
\hline & & $17 / 1$ & טגוד & TY & $r / 0$ & $1 \pi / 9$ & $r Q / 9$ & $\mid r: r_{0}$ & 16 & \\
\hline $0 / 9 \Delta r$ & $r$ r & $r) / r$ & Va)/o & TQ & $0 / 0$ & $\circ / 0$ & $9 / 0$ & $\circ 9: Y_{0}$ & rox & \\
\hline $0 / 401$ & $1 / 1 /$ & $11 / 1$ & V41/० & Tr & $y / 0$ & $9 / 9$ & $r \circ / \varphi$ & $1 Y: r_{0}$ & 141 & \\
\hline
\end{tabular}

بوده است. بهطور مثال مقدار NRMSE براى مــل ســبال برابـر

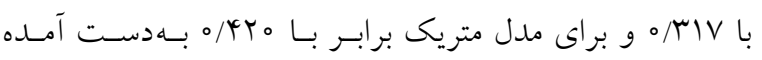
است.

همجينين كمترين (بهترين) مقادير بـراى شـاخصهـاى MAE و ن MBE

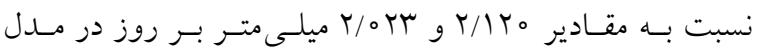

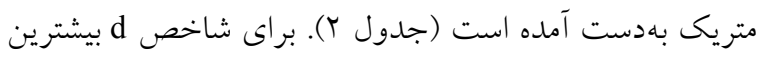

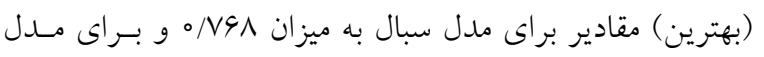

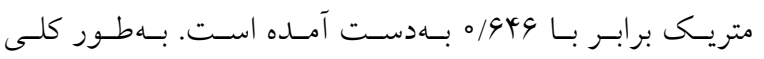

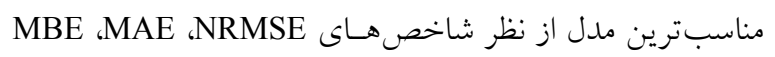

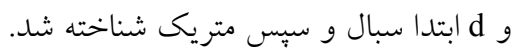

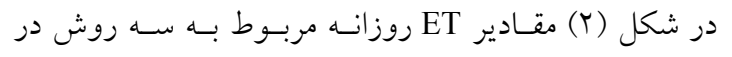

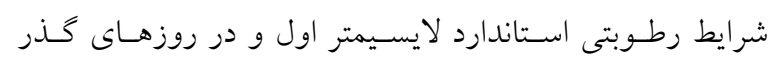

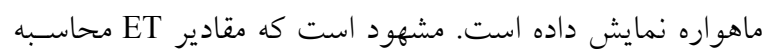

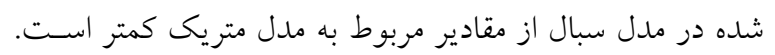

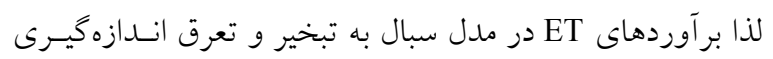

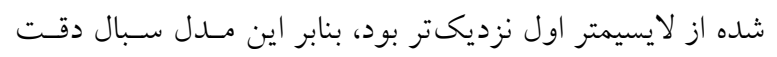

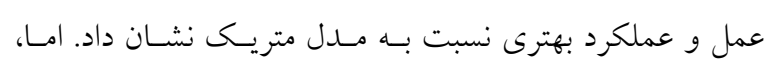

جدول r. مقايسه شاخصهاى برآورد تبخير و تعرق روزانه به روشهاى SEBAL و

\begin{tabular}{|c|c|c|}
\hline \multicolumn{2}{|c|}{ مدل } & \multirow{2}{*}{ شاخص } \\
\hline METRIC & SEBAL & \\
\hline O/AY。 & 落 & NRMSE* \\
\hline T/MO & $1 / 0 \circ r$ & MAE \\
\hline$r / 0 Y r$ & $-\circ / 9 V \mu$ & MBE \\
\hline $0 / 949$ & o/VGA & d \\
\hline
\end{tabular}

\section{نتايج و بحث}

شـاخصهــاى آمـارى از مقايسـه بــين برآوردهــاى ET در

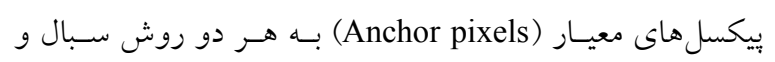

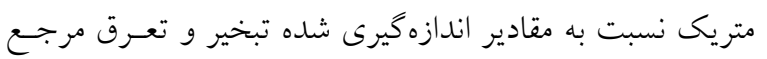

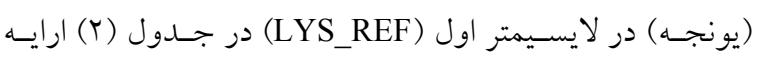
شده است. براسـاس نتـايج ايسـن جــدول، مـــل سـبال از شــاخصهــاى

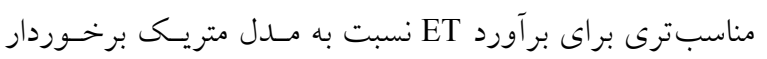




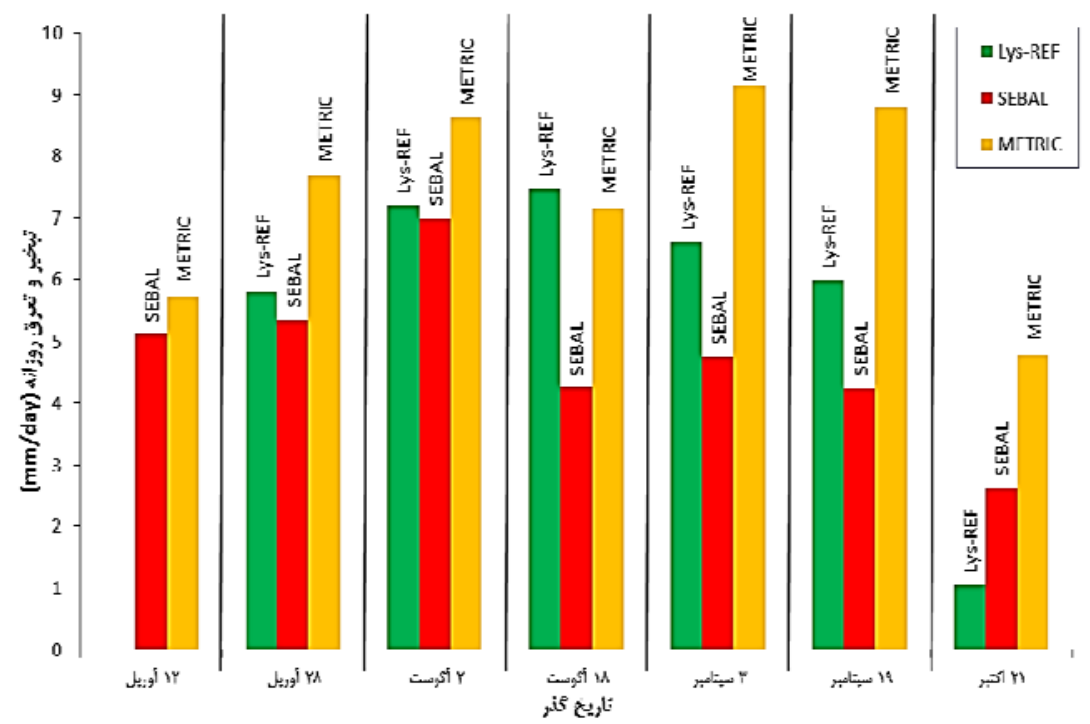

شكل Y. مقايسه تبخير و تعرق در مدلهاى SEBAL و

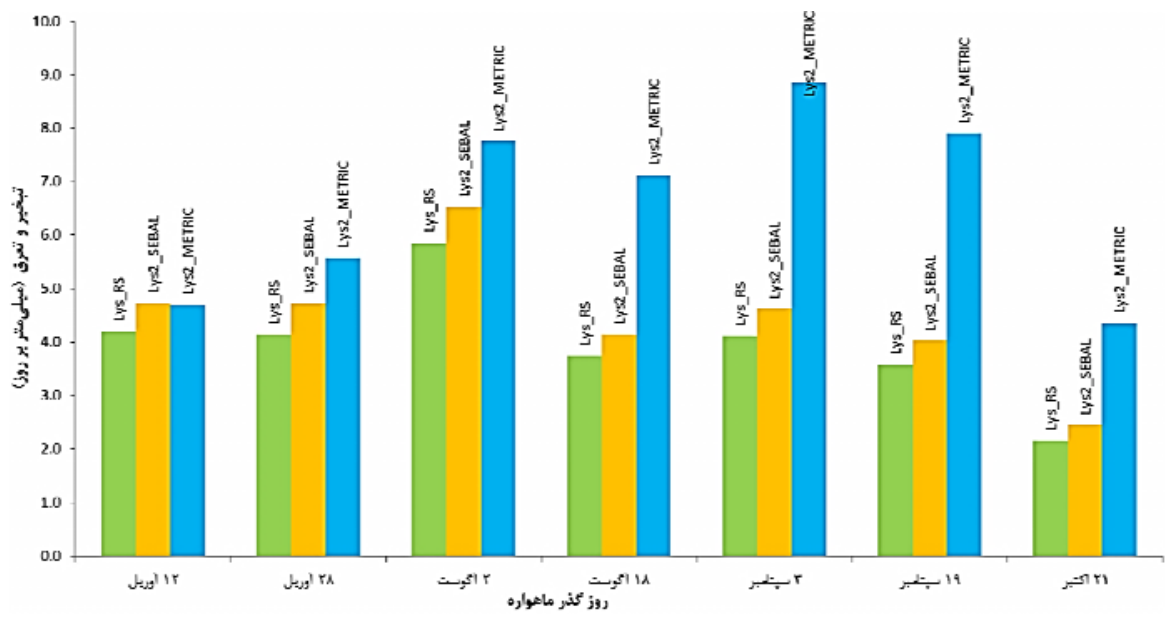

شكل r. مقايسه بين مقادير اندازهيرى شده تبخير و تعرق در لايسيمتر دوم (Lys_RS) نسبت به برآورد مدلهاى SEBAL و

دوم (Lysr_METRIC) در شكل (r) ارايه شده است. با توجــه

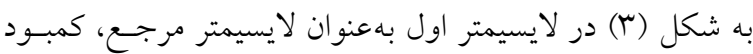

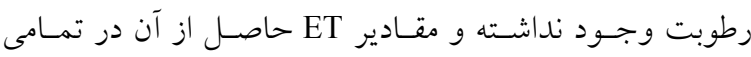

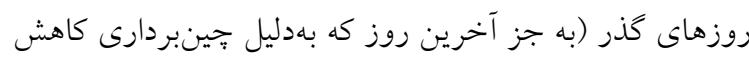

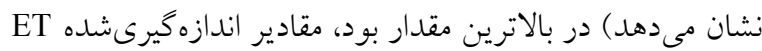
در لايسيمتر دوم بهدليل عدم برقرارى شـرايط استاندارد تـأمين

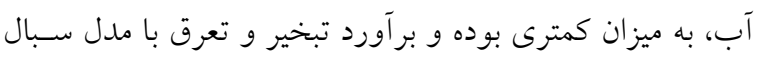

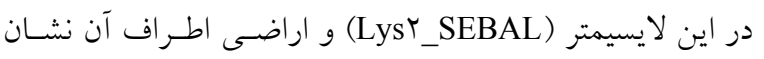

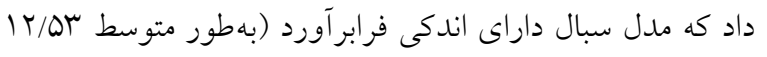

اندازهيرى تبخير و تعرق در لايسيمتر دوم توانسـت اطلاعـات

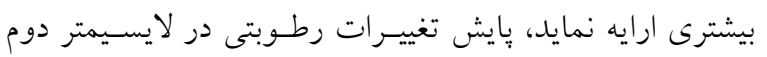

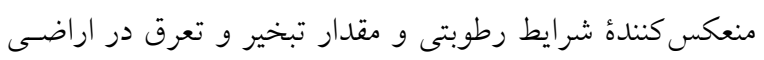

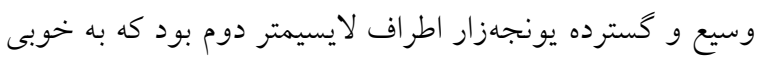

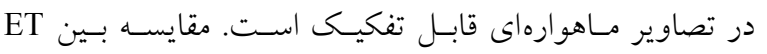

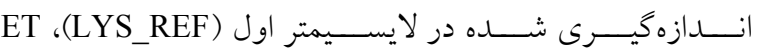

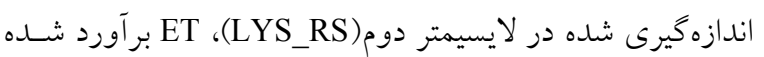

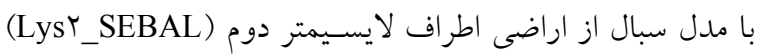

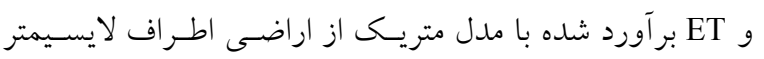


استاندارد براى رشد و تبخير و تعرق برخوردار نبود، بنابر اين با توجه به محاسبات ET در مدل متريك خطاى بيشتر در بـر آورد

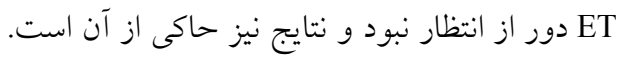

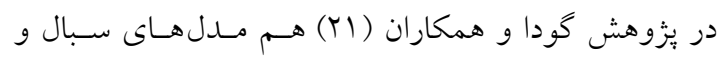

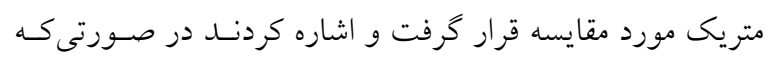

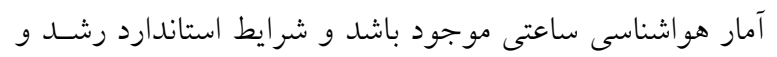

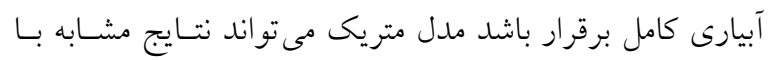

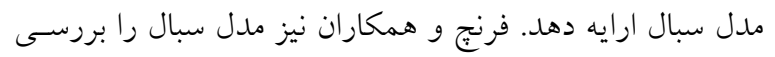

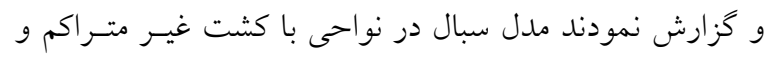

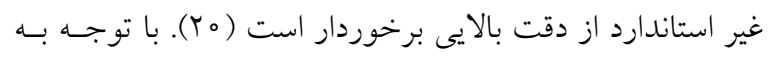

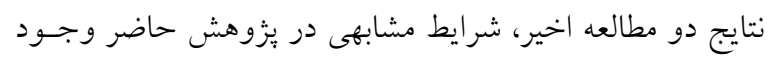

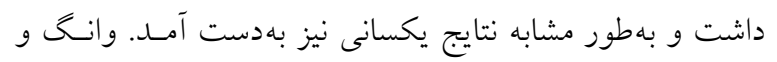

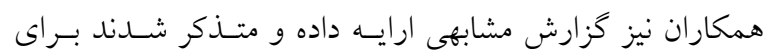

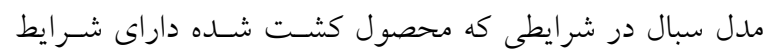

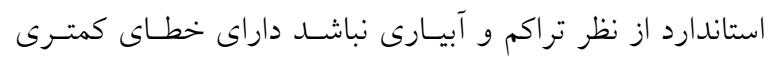

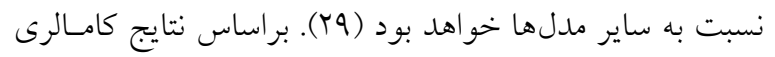

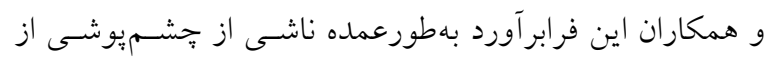

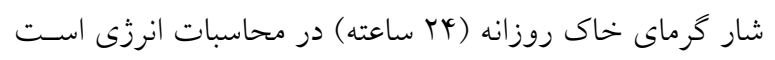

تفاوت در مقادير برآورد ET مربوط به مــلهـــاى سـبال و و

ET متريك در يزوهش ترزا بـهدليـل تفــاوت در نحسوه بــرآورد

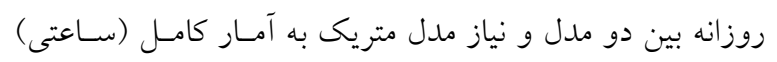

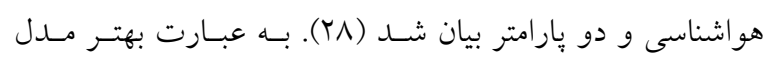

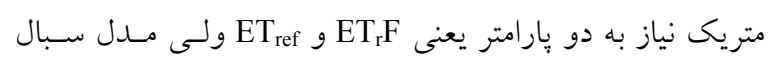

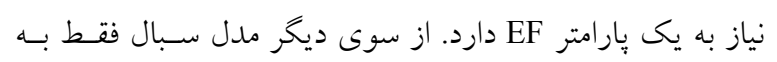

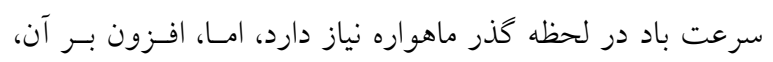

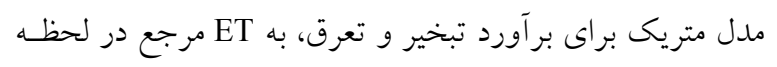

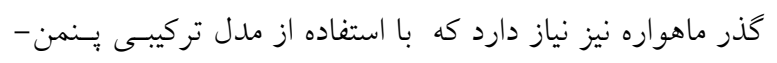

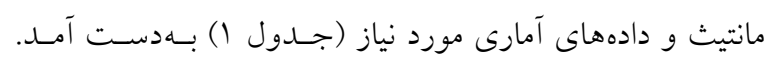

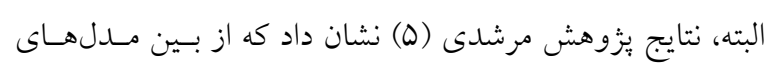

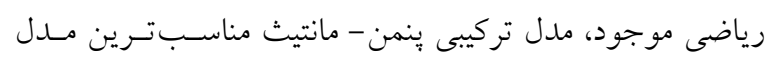
براى دشت شهركرد نبود و براى بازه زمانى روزانـه داراى خطيّا
درصد) در تخمين ET است. از طرفى تبخيـر و تعـرق در مــدل

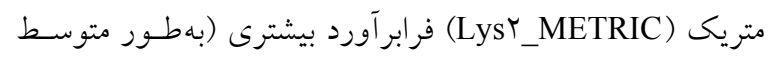

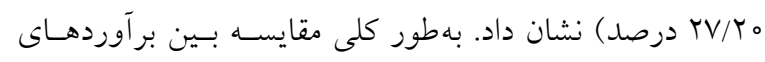

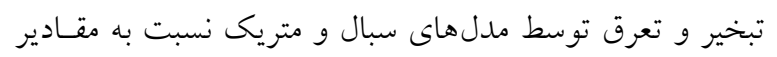

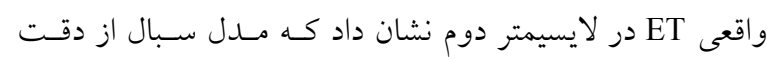

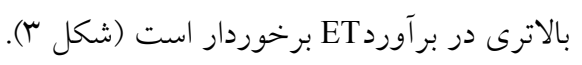

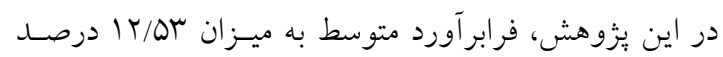

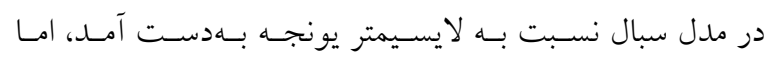

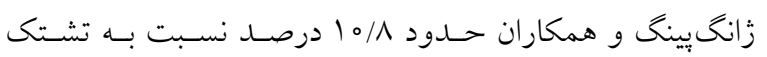
تبخير و لايسيمتر جممن گزارش كردند، تفاوت مـذكور احتمـالا

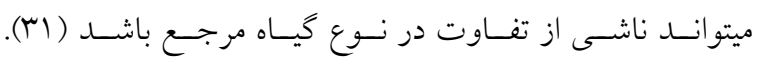

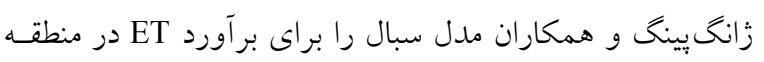

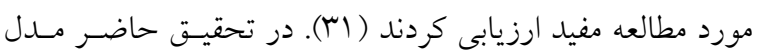
متريك بر آوردهاى بالاترى را نسبت بـه مــدل سـبال ارايسه داد.

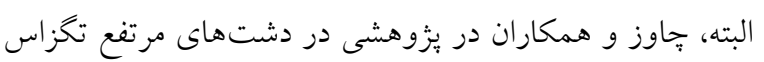

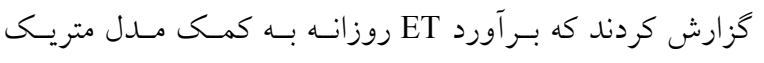

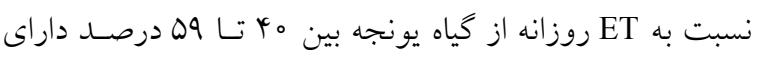

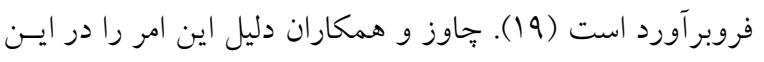

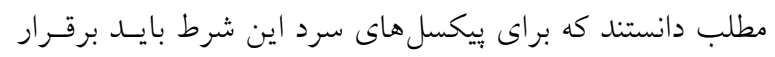
باشـــ كـه ET مرجـع (ET 1.05* ET فرض شود و اين فقط در شرايطى ممكن است كه

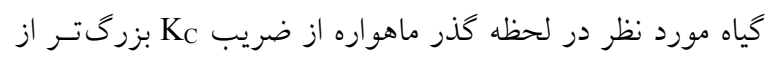

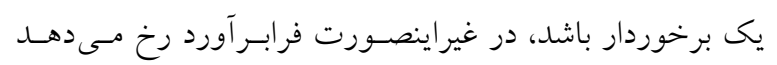

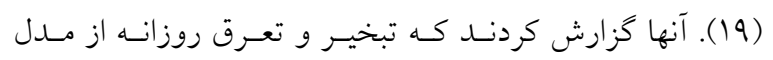
متريك نسبت به نتايج لايسيمترى ذرت تفاوت بارزى را نشـان

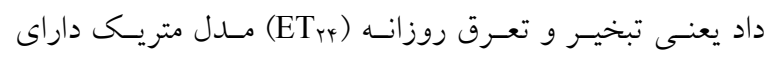

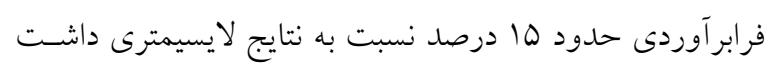

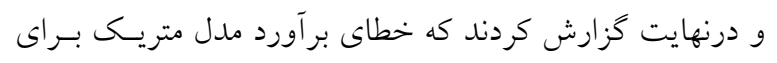

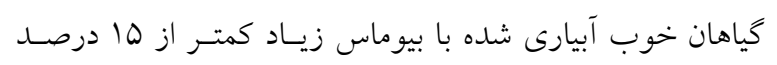

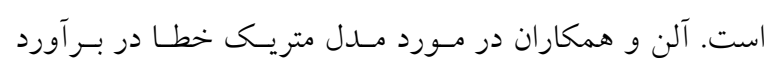

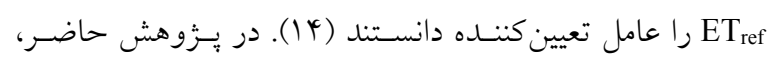

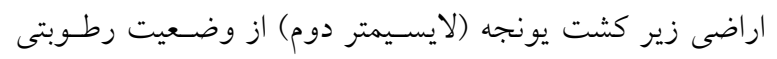


درنظر كرفته مي شود بنابر اين حداكثر مقدار جـز تبخيـ EF در مدل SEBAL برابر با يك خواهد شد. اما براى مدل METRIC مقادير ET F بهصورت معادله (ه) محاسبه مىشود: $\lambda \mathrm{ET}=\mathrm{R}_{\mathrm{n}}-\mathrm{G}_{\circ}-\mathrm{H} \Rightarrow \mathrm{r}_{4} \circ\left(\frac{\lambda \mathrm{ET}}{\lambda}\right)=$

$$
\mathrm{ET}_{\text {inst }} \Rightarrow \mathrm{ETrF}=\frac{\mathrm{ET}_{\text {inst }}}{\mathrm{ET}_{\mathrm{r}}}
$$

براى مدل متريك يارامتر ET و بــرآورد ناصسحيح آن بـهدليـل در دسـت نبـودن آمـار كامـل هو اشناسى (ساعتى) به برآورد ناصحيح باقيمانده انرزى در سطح

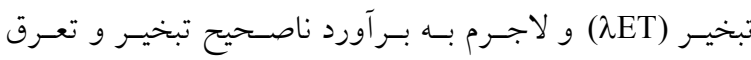
لحظهاى (ET) منجر خواهد شد و درنهايت بـهدليـل مقـادير

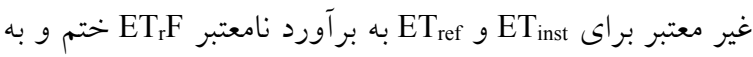

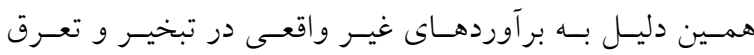

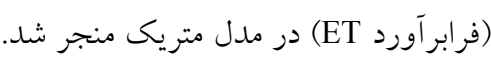

\section{نتيجه گيرى}

نتايج نشـان داد مــل سـبال از كمتـرين مقـادير شـاخصهـاى

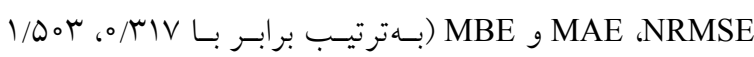
ميلى متر بر روز و سو/9V/ه- ميلى متر بـر روز) و بيشـترين مقـدار

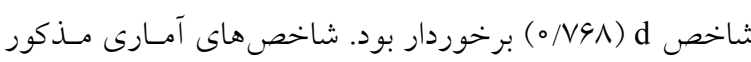

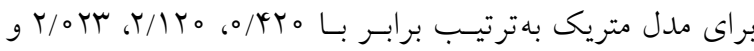

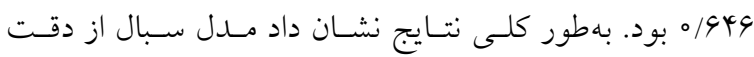
بيشترى در برآورد تبخير و تعرق نسبت به مدل متريـى تحست شرايط حاكم بر دشت شـهركرد برخـوردار بــود. تـا زمـانى كـه. امكان تأمين آمار كامل هواشناسى بهصورت ساعتى فراهم آيد و يا برخى اصلاحات بر مدل متريك انجام شود، نتايج مدل سـبال به واقعيت نزديكتر بوده و لذا مدل سبال توصيه مى شود.
است، بنابر اين برآوردهاى مدل متريك مىتواند همراه با خطاى بيشترى نسبت به مدل سبال انجام كرفته باشد. انتخاب بيكسل مرجع سرد بايستى در اراضى بـا شـاخص سطح برگ بيشتر از \& (LAI > Y)، با بوشش كياهى فشـرده و آبيارى كامـل (بــون تـنش آبسى) باشــ، امـا در زمـان انجـام يزوهش حاضر جنين شرايطى حاكم نبود. به بيان دقيـقتـر، در اوايل فصل رشد و يا فصول غير رشـد كـه شــايط اسـتاندارد براى يوشش كياهى (بــراى انتخــاب بـهـعنـوان بيكسـل سـرد) برقرار نباشد و همينطور ارتفاع گياه به ه/ه متـر (ارتفـاع گيـاه مرجع) نرسيده باشد، خطاى برآورد ET تا مب درصد محتمـل است. در بزظوهش آلن و همكاران نتيجه گيـرى شــ كـه مــدل متريك يكى مدل كامل نبوده و ايرادهـايى بــر آن وارد دانسـتند

براساس آنجهه بِيشـتر بيـان گرديسد، مشـاهدات محلسى در دشت شهركرد حاكى از آن بود كه يوشش كياهى يونجه مـورد بررسى فاقد يوشش كامل بود و بهدليل عدم برقـرارى شـرايط

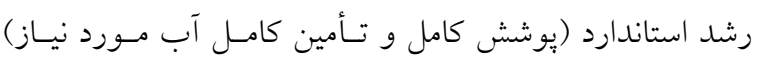
خطاى بيشترى در بر آوردهاى تبخير و تعرق از مـدل متريـى رلـ مشاهده شد. تفاوت قابل بررسى ديخر در مقـدار جـزء تبخيـر اسـت، در مدل سبال جزء تبخير EF و در مدل متريك جزء تبخيـر ET بايد در دامنهاى بين صفر تا يك (حداكثر 1/1) قرار داشته باشــ

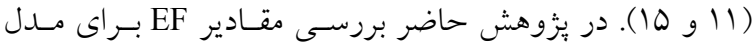

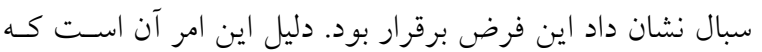
جزء تبخير EF طبق تعريف بهصورت زير محاسبه مىشود: $\mathrm{EF}_{\text {cold }}=\frac{\mathrm{R}_{\mathrm{n}}-\mathrm{G}_{\mathrm{o}}-\mathrm{H}}{\mathrm{R}_{\mathrm{n}}-\mathrm{G}_{\mathrm{o}}} \Rightarrow$ If $\mathrm{H}=\circ \Rightarrow$ Then :

$\mathrm{EF}_{\text {cold }}=\frac{\mathrm{R}_{\mathrm{n}}-\mathrm{G}_{\circ}-\circ}{\mathrm{R}_{\mathrm{n}}-\mathrm{G}_{\circ}}=\frac{\mathrm{R}_{\mathrm{n}}-\mathrm{G}_{\circ}}{R_{\mathrm{n}}-\mathrm{G}_{\circ}}=1 \Rightarrow \circ<\mathrm{EF}<1$

و جون شار گرماى محسوس در يِيكسل هاى سرد برابر با صـفر 


$$
\begin{aligned}
& \text { منابع مورد استفاده } \\
& \text { ا. ثنايىنزاد، س. ح.، س. نورى، و س. م. هاشمىنيا. •وبا. برآورد تبخير و تعرق واقعى با استفاده از تصـاوير مـاهوارهاى در منطقـه } \\
& \text { مشهد. نشريه آب و خاك (علوم و صنايع كشاورزى) هY(Y): }
\end{aligned}
$$

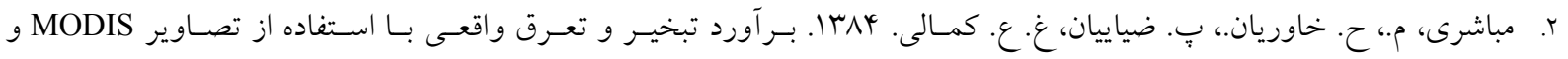

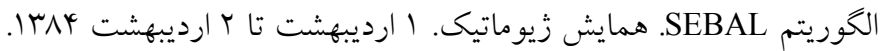

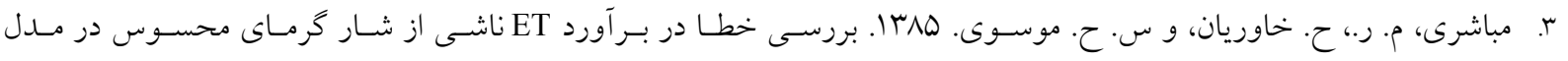

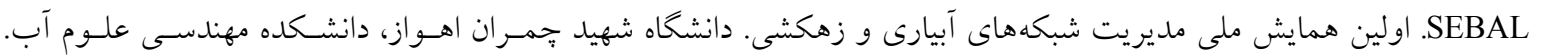

$$
\begin{aligned}
& \text { اهواز. ب ا ارديبهشت تا عا ارديبهشت هیربا. }
\end{aligned}
$$

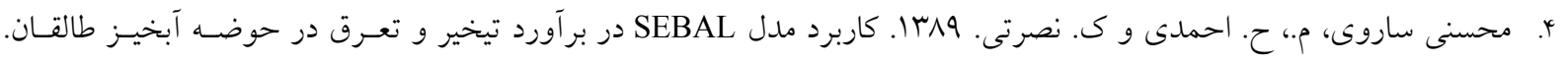

$$
\begin{aligned}
& \text { اولين كنفر انس بين المللى مدلسازى گياه، آب، خاك و هوا. مركز بين المللى علوم و تكنولوزى بيشرفته و علوم محيطى. دانشـحاه } \\
& \text { شهيد باهنر كرمان. بr آبان تا ع آبان } \\
& \text { ه. مرشدى، ع. الوسا. تخمين و بهيهن بندى ميزان تبخير و تعـرق واقعى بـا اسـفاده از داده هـاى سـنجش از دور در دشـت شهركرد. }
\end{aligned}
$$

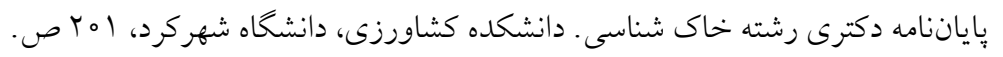

$$
\begin{aligned}
& \text { و. نورى، س.، ح. ثنايىنزاد و م. هاشمىنيا. ولها. برآورد تبخير و تعرق واقعى در مقياس منطقهاى با استفاده از الخوريتم SEBAL و }
\end{aligned}
$$

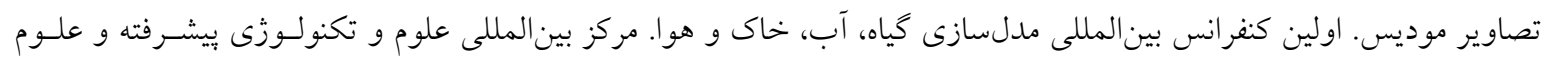

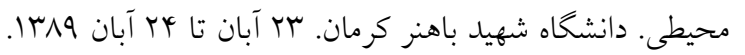

7. Akbari, M., N. Toomanian, P. Droogers, W. Bastiaanssen and A. Gieske. 2007. Monitoring irrigation performance in Esfahan, Iran, using NOAA satellite imagery. Agric. Water. Man. 88: 99-109.

8. Allen, R. G., L. S. Pereira, D. Raes and M. Smith. 1998. Crop evapotranspiration Guidelines for computing crop water requirements, FAO Irrigation and Drainage pp: 5627-65.

9. Allen, R. G., M. Tasumi and R. Trezza. 2005a. METRIC: mapping evapotranspiration at high resolution applications manual for Landsat satellite imagery. University of Idaho: Kimberly.

10.Allen, R. G., M. Tasumi, A. Morse and R. Trezza. 2005b. A Landsat-based energy balance and evapotranspiration model in Western US water rights regulation and planning. Irri. Drain. Sys. 19: 251-268.

11.Allen, R. G., M. Tasumi and A. Morse. 2005c. A. Satellite-based evapotranspiration by METRIC and Landsat for western states water management. Presented at the US Bureau of Reclamation Evapotranspiration Workshop, Ft. Collins, CO, USA.

12.Allen, R. G., M. Tasumi and R. Trezza. 2007. Satellite-based energy balance for mapping evapotranspiration with internalized calibration (METRIC)-model. J. Irrig. Drain. Eng. 133: 380-394.

13. Allen, R. G., Morse, A., Tasumi, M., Bastiaanssen, W., Kramber, W. and Anderson, H. 2001. Evapotranspiration from Landsat (SEBAL) for water rights management and compliance with multi-state water compacts. International Geoscience and Remote Sensing Symposium, 2, 830-833.

14. Allen, R. G., A. Irmak, R. Trezza, J. M. H. Hendricks, W. Bastiaanssen and J. Kjaersgaard. 2011. Satellite-based ET estimation in agriculture using SEBAL and METRIC. Hydrol. Process. 25: 4011-4027.

15. Bastiaanssen, W. G. M. 1995. Regionalization of surface flux densities and moisture indicators in composite terrain. Ph.D. Thesis, Wageningen Agricultural University: Wageningen. The Netherlands.

16. Bastiaanssen, W. G. M., H. Pelgrum, J. Wang, Y. Ma, J. F. Moreno, G. J. Roerink and W. T. van der. 1998a. A Surface Energy Balance Algorithm for Land (SEBAL): Part 2 validation. J. Hydrol. 212-213: 213-229.

17. Bastiaanssen, W. G. M., M. Menenti, R. A. Feddes and A. A. M. Holtslag. 1998b. A remote sensing surface energy balance algorithm for land (SEBAL): 1. Formulation. J. Hydrol. 212-213: 198-212.

18. Cammalleri, C., G. Ciraolo, G. La Loggia and A. Maltes. 2012. Daily evapotranspiration assessment by means of residual surface energy balance modeling: A critical analysis under a wide range of water availability. J. Hydrol. 452-453: 119-129. 
19. Chavez, J. L., P. H. Gowda, T. A. Howell, T. H. Marek and L. L. New. 2007. Evapotranspiration mapping using METRIC for a region with highly advective conditions. In proceedings of the 2007 Annual International ASABE Meeting, Centennial Celebration. Paper No. 072146. June 17-20, 2007. Minneapolis, MN.

20. French, A. N., F. Jacob, M.C. Anderson, W.P. Kustas, W. Timmermans, A. Gieske, Z. Su, H. Su, M.F. McCabe, F. Li, J. Prueger, N. Brunsell. 2005. Surface energy balance fluxes with the Advanced Spaceborn Thermal Emmisssion and Reflection radiometer (ASTER) at the Iowa 2002 SMACEX site (USA). Remote sensing Environ. 99(1-2): 55-65.

21. Gowda, P. H., Chavez, J. L. Colaizzi, P. D. Evett, S. R. Howell, T. A. and J. A. Tolk. 2008. ET mapping for agricultural water management: present status and challenges. Irrig. Sci. 26(3): 223-237.

22. Hexagon Geospatial. ERDAS Imagine, Version 2010. 5051 Peachtree Corners Circle. Norcross, GA 30092-2500. USA.

23. IBM Corp. Released 2015. IBM SPSS Statistics for Windows, Version 24.0. Armonk, NY: IBM Corp. USA.

24. Itenfisu, D., R.L. Elliot, R.G. Allen and I.A. Walter. 2003. Comparison of reference evapotranspiration calculations as part of the American Society of Civil Engineers standardization effort. J. Irrig. Drain. Eng., 129(6):440-448.

25. Jensen, M. E., R. D. Burman and R. G. Allen. 1990. Evapotranspiration and irrigation water requirements. American Society of Civil Engineers Manuals and Reports on Engineering Practices No. 70, American Society of Civil Engineers, New York.

26. Mokhtari, M. H. 2005. Agricultural drought impact using remote sensing. Ms. C. Diss., ITC. The Netherlands.

27. Temesgen, B., R. G. Allen and D.T. Jensen. 1999. Adjusting temperature parameters to reflect well-watered conditions. J. Irrig. Drain. Eng. 125(1): 26-33.

28. Trezza, R. 2006. Estimation of evapotranspiration from satellite-based surface energy balance models for water management in the Rio Guarico irrigation system, Venezuela. Earth observation for vegetation monitoring and water management. The American Institute of Physics Conference Proceeding. 852 (1): 162-169.

29. Wang, J., T. W. Sammis, V. P. Gutschick, M. Gebremichael and D. R. Miller. 2009. Sensitivity analysis of the surface energy balance algorithm for land (SEBAL). Am. Soc. Agric. Biol. Eng. 52 (3):801-811.

30. Zhao-Liang, L., T. Ronglin, W. Zhengming, B. Yuyun, Z. Chenghu, T. Bohui, Y. Guangjian and Z. Xiaoyu. 2009. A review of current methodologies for regional evapotranspiration estimation from remotely sensed data. Sensors 9: 3801-3853.

31. Zhongping, S., B. Wei, W. Su, W. Shen, C. Wang, D. You and, Z. Liu. 2011. Evapotranspiration estimation based on the SEBAL model in the Nansi Lake Wetland of China. Math. Comp. Model. 54: 1086-1092. 


\title{
Estimation of Reference Evapotranspiration at Regional Scale using Remote Sensing Data in Shahrekord Plain I- Comparing the Results of SEBAL and METRIC Models to Lysimetric Measurements
}

\author{
A. Morshedi ${ }^{*}$, M. Naderi ${ }^{2}$, S.H. Tabatabaei ${ }^{3}$ and J. Mohammadi ${ }^{2}$
}

(Received: Sept. 06-2014; Accepted: Aug. 03-2016)

\begin{abstract}
Conventional methods for estimating evapotranspiration are based on point measurement and suitable for local areas, therefore, cannot be generalized for larger areas or watershed basins. The remote sensing technology is capable of using satellite images and meteorological data to estimate evapotranspiration in a wider area. In this study, estimates of evapotranspiration (ET) by SEBAL and METRIC models based on Landsat 7 ETM+ sensor were compared against ET measured by lysimeter on seven satellites passing time over Shahrekord plain located in Karun basin. The results showed that the lowest indices of NRMSE, MAE and MBE (respectively, 0.317, 1.503 and -0.973 mm per day) and the maximum of $d$ index (0.768) belonged to SEBAL. These indices were 0.420, 2.120, 2.023 and 0.646 for METRIC, respectively. The results showed that the SEBAL was more accurate than METRIC model for estimating ET under Shahrekord plain conditions. As long as the possibility of getting complete hourly meteorological data be provided, or some modifications on METRIC model were done, SEBAL show closer results to reality, and therefore is recommended.
\end{abstract}

Keywords: Satellite imagery, Landsat, Surface energy balance, Alfalfa.

1. Dept. of Soil and Water Res., Chaharmahal and Bakhtiari Agric. and Natural Resour. Res. Center, AREEO, Shahrekord, Iran.

2. Dept. of Soil Sci., College of Agric., Shahrekord Univ., Shahrekord, Iran.

3. Dept. of Water Eng., College of Agric., Shahrekord Univ., Shahrekord, Iran.

*: Corresponding Author, Email: a.morshedi@areeo.ac.ir 